\title{
SUBSTANTIATION OF CONDITIONS AND FACTORS FOR REDUCING REGIONAL DIFFERENTIATION OF INNOVATIVE ACTIVITY
}

\author{
Maxim N. Osovin \\ Institute of Agrarian Problems of the Russian Academy of Sciences, Saratov, Russian Federation
}

\begin{abstract}
A comparative analysis of innovation activity in the Russian Federation and EU countries is carried out. The comparison revealed that modern innovation policy should be aimed not only at increasing labor productivity, but also at solving social problems related to ensuring food security, environmental protection and improving the quality of life of the population. Maintaining a balance between the demand for digital technology and the supply of high-tech products on the market is a basic element in the transition to a new stage of scientific and technological structure. Factors that negatively affect the development and implementation of technological, organizational and marketing innovations are identified. It is shown that the synchronization of the chain of implementation of all newly created or improved technologies ensuring the continuity of the innovation cycle requires the combined efforts of all subjects of innovation. The level of diffusion of innovative activity in federal districts of the Russian Federation is estimated. It is concluded that there is a significant differentiation of regional and sectoral intensity of innovative development. It is substantiated that in order to reduce regional differentiation when introducing advanced practices into the production process, one should take into account the type of innovative activity. According to the attractiveness for investment, digital economy instruments are divided into three categories that characterize one or another stage of their life cycle: maturity, sustainable growth, and a breakthrough trend. It was revealed that the further massive penetration of technological innovations into all links of the production chain should clearly follow the global trends of production digitalization, where the key factor for the success of innovation-oriented companies is the search for the most promising investment projects at the stage of filing a patent application. Based on the analysis, recommendations were developed to stimulate innovative susceptibility in the regions of Russia.
\end{abstract}

Key words: innovative susceptibility, regional differentiation, diffusion of innovations, digital economy, labor productivity, quality of life, human capital.

Citation. Osovin M.N. Substantiation of Conditions and Factors for Reducing Regional Differentiation of Innovative Activity. Journal of Volgograd State University. Economics, 2020, vol. 22, no. 3, pp. 65-76. (in Russian). DOI: https://doi.org/10.15688/ek.jvolsu.2020.3.6

\section{ОБОСНОВАНИЕ УСЛОВИЙ И ФАКТОРОВ СНИЖЕНИЯ РЕГИОНАЛЬНОЙ ДИФФЕРЕНЦИАЦИИ ИННОВАЦИОННОЙ АКТИВНОСТИ}

\author{
Максим Николаевич Осовин \\ Институт аграрных проблем РАН, г. Саратов, Российская Федерация
}

Аннотация. В рамках данного исследования проведен сравнительный анализ инновационной активности в Российской Федерации и странах Евросоюза. При сопоставлении выявлено, что современная инновационная политика должна быть нацелена не только на рост производительности труда, но и на решение социальных проблем, связанных с обеспечением продовольственной безопасности, охраной окружающей среды и повышением качества жизни населения. Отмечено, что соблюдение баланса между спросом на цифровые технологии и предложением на рынке высокотехнологической продукции выступает базовым элементом перехода к новой стадии научно-технологического уклада. Определены факторы, негативно вли- 
яющие на разработку и внедрение технологических, организационных и маркетинговых инноваций. Показано, что синхронизация цепочки внедрения всех вновь созданных или усовершенствованных технологий, обеспечивающая непрерывность инновационного цикла, требует объединения усилий всех субъектов инновационной деятельности. Проведена оценка уровня диффузии инновационной активности по федеральным округам Российской Федерации. Сделан вывод о значительной дифференциации региональной и отраслевой интенсивности инновационного развития. Обосновано, что для сокращения региональной дифференциации при внедрении передовых практик в производственный процесс следует учитывать тип инновационной активности. По привлекательности для инвестирования инструменты цифровой экономики разделены на три категории, характеризующие ту или иную стадию их жизненного цикла: зрелость, устойчивый рост, прорывной тренд. Выявлено, что дальнейшее массовое проникновение технологических инноваций во все звенья производственной цепочки должно четко следовать общемировым трендам цифровизации производства, где ключевым фактором успеха инновационно ориентированных компаний является поиск наиболее перспективных инвестиционных проектов еще на этапе подачи патентной заявки. На основе проведенного анализа разработаны рекомендации по стимулированию инновационной восприимчивости в регионах России.

Ключевые слова: инновационная восприимчивость, региональная дифференциация, диффузия инноваций, цифровая экономика, производительность труда, качество жизни, человеческий капитал.

Цитирование. Осовин М. Н. Обоснование условий и факторов снижения региональной дифференциации инновационной активности // Вестник Волгоградского государственного университета. Экономика. 2020. - T. 22, № 3. - C. 65-76. - DOI: https://doi.org/10.15688/ek.jvolsu.2020.3.6

\section{Введение}

В современном мире цифровые технологии уже давно превратились из локального инструмента, замещающего человека на отдельных этапах процесса производства, в ключевой драйвер экономического роста. Анализ российских и международных программ [Цифровая экономика ...; Стратегия инновационного развития ...; Стратегия развития информационного общества ...; Europe 2020 Strategy], призванных стимулировать процесс цифровизации, показал, что глобальным трендом цифрового развития является стремление к достижению технологического лидерства во всех сферах и отраслях народного хозяйства, а также соблюдение баланса между постоянно растущим уровнем внутреннего спроса на квалифицированные кадры и качеством профессиональных навыков и компетенций большей части населения в сфере высоких технологий. Сочетание данных направлений обеспечивает симбиоз знаний и технологий, составляющих основную ценность инновационно ориентированной экономики, стимулирует восприимчивость бизнеса к изменениям внешней среды, способствует насыщению рынка труда и улучшению качества жизни населения.

Глобальный инновационный ландшафт меняется, инвестиции в образование и человеческий капитал за последние три десятилетия значительно увеличились, а расходы на
НИОКР за период с 1996 по 2017 г. выросли практически вдвое [The Global Innovation Index .... П. При этом если в середине 1990-х гг. на долю стран с высоким уровнем дохода приходилось 87 \% мировых инвестиций на научные исследования, то в 2017 г. они составили лишь $64 \%$ от общего объема. В странах с уровнем дохода выше среднего расходы на НИОКР увеличиваются более интенсивно. В 1996 г. их доля не превышала 10 \%, но за следующее десятилетие она выросла до 31 \%. Страны Юго-Восточной Азии (Китай, Япония, Республика Корея и Индия) обеспечили в 2017 г. до 40 \% мировых НИОКР (22 \% в 1996 г.), из которых на долю Китая приходилось 24 \% мировых расходов на НИОКР (2,6 \% в 1996 г.), а Индии - 2,9 \% (1,8 \% в 1996 г.). Государственное финансирование НИОКР остается центральным элементом создания будущих прорывных технологий, но за последние годы стремительно увеличивается интерес к инвестированию в научные исследований и разработки со стороны частного сектора. В 2017 г. на долю США, Китая, Японии, Республики Корея, Германии, Франции, Великобритании и Индии пришлось $82 \%$ инвестиций частного сектора в НИОКР.

К числу положительных общемировых тенденций можно также отнести рост количества исследователей. С 2008 по 2016 г. их число в расчете на 1 млн жителей выросло на 19 \%, при этом наибольший вклад в этот рост 
внесли страны со средним уровнем дохода, число исследователей в которых за тот же период увеличилось на $34 \%$. Более того, если в 1997 г. 88 \% всех патентных заявок поступали из стран с высоким уровнем дохода, то в 2017 г. происхождение патентных заявок было почти одинаково распределено между странами с высоким и верхним средним уровнем дохода, а доля патентов, зарегистрированных на территории Китая, за тот же период выросла с 2 до $44 \%$.

В качестве инструментария, позволяющего оценить интенсивность инновационной деятельности, целесообразно использовать The Global Innovation Index (Глобальный инновационный индекс) [The Global Innovation Index ...], который включает показатели по 129 странам мира. Показатели индекса позволяют оценить факторы, влияющие как на внедрение инноваций, так и на их распространение. В свою очередь, субиндекс внедрения инноваций состоит из пяти основных компонентов, обеспечивающих инновационную деятельность: институтов, человеческого капитала и научных исследований, инфраструктуры, сложности рынка и сложности ведения бизнеса. Субиндекс распространения инноваций содержит информацию о продукции, которая является результатом инновационной деятельности внутри стран, и оценивает интенсивность создания новых знаний и технологий, а также творческую деятельность.

Швейцария лидирует в рейтинге уже девятый год подряд, в то время как Швеция в 2019 г. возвращается на 2-ю позицию, а США поднимаются на 3-е место. К топ-20 уверенно приближается Республика Корея, а Китай перемещается с 17-го на 14-е место, претендуя в ближайшем будущем на лидерские места.

Российская Федерация второй год подряд сохраняет 46-е место в глобальном инновационном рейтинге, при этом она улучшила свои позиции по субиндексу «Внедрение инноваций», поднявшись на 2 пункта (41-е место), но по сравнению с прошлым годом потеряла 3 позиции по субиндеку «Распространение инноваций», опустившись на 59-е место. В инфраструктурном компоненте Россия занимает 62-е место, по уровню использования информационно- коммуникационных технологий - 45-е место, по уровню предоставления государственных услуг в электронном виде 25-е место. Благодаря высокому уровню охвата населения высшим образованием и доле выпускников технических специальностей, Россия занимает традиционно высокие места при оценке уровня развития человеческого капитала (23-е место), но по уровню расходов на образование - лишь 86-е место, по доле негосударственных расходов на исследования и разработки - 58-е место, по уровню доступа к продуктам и услугам информационнокоммуникационных технологий (далее ИКТ) - 51-е место, что, с нашей точки зрения, повлияло не только на скорость распространения знаний посредством современных технологий (63-е место), но и на формирование инновационных связей между наукой и производством (93-е место).

Аналогичные выводы можно сделать, если взять за основу анализа инновационной деятельности международный индекс цифровой конкурентоспособности [IMD ...]. В 2019 г. его возглавили США, но по сравнению с 2013 г. Россия также упрочила свои позиции в рейтинге, сместившись с 46-го на 38-е место. К числу положительных трендов можно отнести прорыв в группах «Обучение и образование» (с 19-го до 9-го места) и «Уровень научно-технической активности» (с 23-го до 18-го места), однако условия для адаптации бизнеса к изменениям внешней среды все еще не соответствуют мировым стандартам (54-е место), по общему объему государственных расходов на образование Россия занимает 48-е место, по затратам на обучение сотрудников - 45-е место, по привлекательности для зарубежных специалистов - 54-е место, а по оценке цифровых технологических навыков населения 42-е место.

Таким образом, завоевание рынка высоких технологий - это часть политических амбиций большинства стран мира. Северная Америка и Европа продолжают возглавлять мировые рейтинги, оценивающие уровень инновационной деятельности и цифровой конкурентоспособности, и за последнее десятилетие только Китай смог потеснить ряд лидеров. Мировая практика показывает, что экономика с диверсифицированной экспортной корзиной, выходящей за рамки нескольких сырьевых товаров, является более инновацион- 
ной. Поэтому при выборе приоритетных направлений дальнейшего совершенствования цифровой архитектуры в Российской Федерации необходимо ориентироваться на снижение отраслевой и региональной дифференциации по уровню инновационной деятельности, опираться на национальную специфику распространения инноваций и обратить особое внимание на продвижение собственной инклюзивной инновационной продукции.

\section{Результаты и обсуждение}

В 2017 г. совокупный уровень инновационной активности в России составил 8,5\%, сократившись по сравнению с 2015 г. на 0,8 \%, тогда как в Канаде он превысил 79 \% от всех обследованных организаций, в Швейцарии 72,6 \%, в Норвегии - 71,0 \%. Совокупный уровень организаций, которые осуществляют технологические инновации, воплощенные в виде новых либо усовершенствованных продуктов или услуг, процессов или способах производства, снизился с 8,3 до 7,5 \% (Бельгия -62,1\%, Норвегия - 60,4\%, Португалия - 58,5 \%). Новые методы ведения бизнеса, направленные на повышение эффективности деятельности организации за счет сокращения административных и трансакционных издержек и стимулирующие производительность труда, применяли лишь 2,3 \% обследованных организаций $(2,7 \%$ в 2015 г.), тогда как в Бразилии этот показатель достиг 58,9 \%, в Швейцарии $42,4 \%$, в Австрии - 41,1 \% [Индикаторы инновационной деятельности, 2019; Наука ... , 2019].

Если рассматривать ситуацию в отраслевом разрезе, то в промышленном производстве технологические инновации осуществлялись лишь на 9,6 \% предприятий, организационные - на 2,8 \%, а маркетинговые - на 1,8 \%. Нововведения, направленные на повышение экологической безопасности в процессе производства или в результате использования усовершенствованной продукции, были внедрены на 13,7 \% промышленных предприятий, при этом в расчет принимались лишь организации, осуществлявшие инновационную деятельность любого типа в течение последних трех лет. Аналогичная ситуация складывается в сфере услуг $(6,3 \%, 2 \%, 1,2 \%$ и $8,4 \%$ соответственно) и в сельском хозяйстве $(3,1 \%$, $0,9 \%, 0,5 \%$ и $3,6 \%$ соответственно) (рис. 1 ).

На основе официальных статистических данных была проведена оценка уровня диффузии инноваций по федеральным округам Российской Федерации. Для удобства сопоставления все параметры сгруппированы по типам инноваций и области применения вокруг усредненного параметра, которому присвоено значение 0.

Распределение отклонений от усредненного параметра по первой квалификационной группе «Совокупный уровень инновационной активности» представлено в таблице 1.

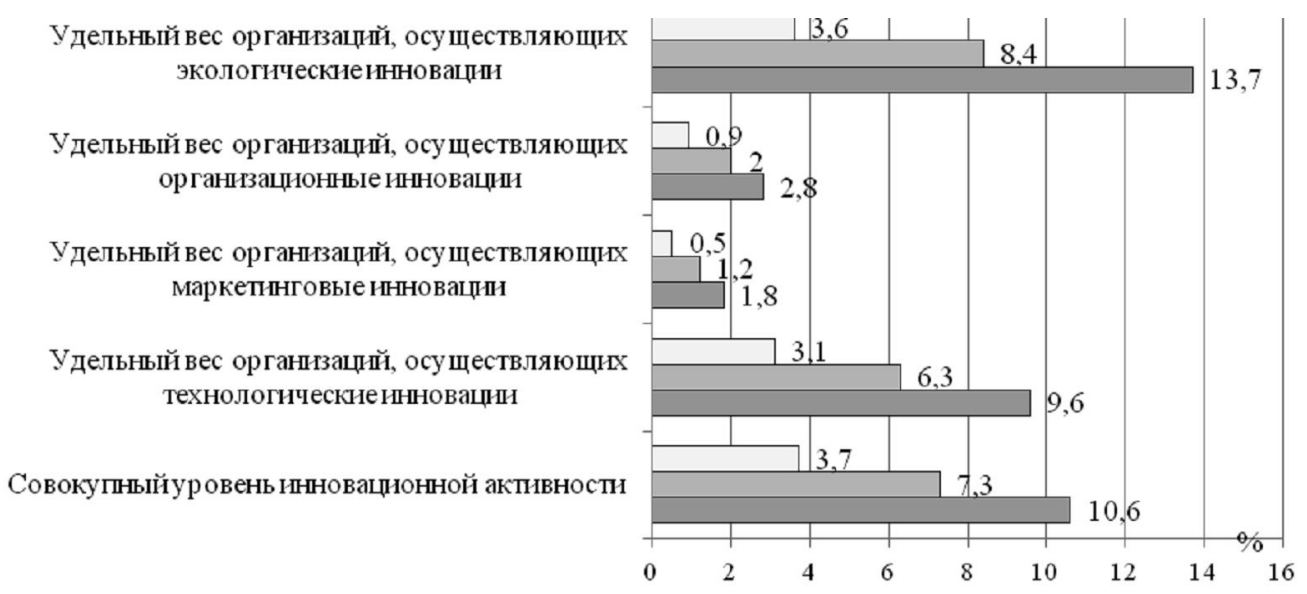

Сельскоехозяйство $\square$ Виды экономнческой деятельности сферы услуг $\square$ Промышленноепр оизводство

Рис. 1. Совокупный уровень инновационной активности и удельный вес организаций, осуществляющих инновации отдельных типов, в общем числе организаций, \%

Примечание. Составлено автором по: [Индикаторы инновационной деятельности, 2019]. 
М.Н. Осовин. Снижение региональной дифференциации инновационной активности

Таблица 1

Распределение федеральных округов Российской Федерации по совокупному уровню инновационной активности

\begin{tabular}{|c|c|c|c|c|c|c|}
\hline \multirow[t]{2}{*}{ Федеральный округ } & \multicolumn{2}{|c|}{$\begin{array}{c}\text { Промышленное } \\
\text { производство }\end{array}$} & \multicolumn{2}{|c|}{$\begin{array}{c}\text { Виды экономической } \\
\text { деятельности сферы услуг }\end{array}$} & \multicolumn{2}{|c|}{$\begin{array}{l}\text { Сельское } \\
\text { хозяйство }\end{array}$} \\
\hline & $x_{i}$ & $x-\bar{x}$ & $x_{j}$ & $x_{j}-$ & $x_{k}$ & $x_{k}-$ \\
\hline Центральный ФО & 11,6 & 2,06 & 9,2 & 2,55 & 4,7 & 1,15 \\
\hline Северо-Западный ФО & 9,5 & $-0,04$ & 8,3 & 1,65 & 4,0 & 0,45 \\
\hline Южный ФО & 10,7 & 1,16 & 7,3 & 0,65 & 5,0 & 1,45 \\
\hline Северо-Кавказский ФО & 3,5 & $-6,04$ & 4,5 & $-2,15$ & 1,3 & $-2,25$ \\
\hline Приволжский ФО & 11,9 & 2,36 & 7,0 & 0,35 & 3,0 & $-0,55$ \\
\hline Уральский ФО & 11,2 & 1,66 & 5,4 & $-1,25$ & 4,6 & 1,05 \\
\hline Сибирский ФО & 9,3 & $-0,24$ & 6,0 & $-0,65$ & 3,4 & $-0,15$ \\
\hline Дальневосточный ФО & 8,6 & $-0,94$ & 5,5 & $-1,15$ & 2,4 & $-1,15$ \\
\hline Среднее по ФО ( ) & \multicolumn{2}{|c|}{9,54} & \multicolumn{2}{|c|}{6,65} & \multicolumn{2}{|c|}{3,55} \\
\hline $\begin{array}{l}\text { Среднеквадратичное } \\
\text { отклонение }(S)\end{array}$ & \multicolumn{2}{|c|}{2,53} & \multicolumn{2}{|c|}{1,49} & \multicolumn{2}{|c|}{1,20} \\
\hline
\end{tabular}

Примечание. Рассчитано автором по: [Индикаторы инновационной деятельности, 2019].

Поскольку объем выборки небольшой, то для построения нормирующего интервала для каждой группы параметров использовался метод расчета среднеквадратичного отклонения от результирующего индикатора:

$$
S=\sqrt{\frac{1}{n} \sum_{i=1}^{n}\left(x_{i}-\bar{x}\right)^{2}}
$$

где $x_{i}-i$-й элемент выборки; $n$ - объем выборки, равный количеству федеральных округов; $\bar{x}$-среднеарифметический параметр выборки, рассчитанный по формуле

$$
\bar{x}=\frac{1}{n} \sum_{i=1}^{n} x_{i}=\frac{1}{n}\left(x_{1}+\ldots+x_{n}\right)
$$

В экономике и сфере финансов среднеквадратичное отклонение в большую или меньшую сторону отождествляется с риском. Плотность вероятности нормального распределения и процент попадания анализируемой величины на отрезки, равные однократному среднеквадратичному отклонению, составляет $34,1 \%$, двукратному - $13,6 \%$, а вероятность того, что величина отклонится от среднего значения более чем в три раза, - менее $1 \%$.

Подавляющая часть административнотерриториальных единиц Российской Федерации попадает в стандартную вилку однократного среднеквадратичного отклонения, равного 2,53 пункта для промышленного производства, 1,49 - для видов деятельности сферы услуг, 1,2 - для сельского хозяйства.
Центральный и Северо-Западный федеральные округа являются лидерами по уровню инновационной активности в сфере услуг (9,2 \% и 8,5 \% обследованных предприятий при среднем уровне 6,65 \%), Южный федеральный округ - в сельском хозяйстве (5\% при среднем уровне $3,55 \%$ ). Однако внедрение инноваций в промышленное производство в Северо-Кавказском федеральном округе демонстрирует отклонение от нормы более чем в 2,3 раза, в сфере услуг - 1,44 раза, в сельском хозяйстве $-1,8$ раза.

Распределение административно-территориальных единиц РФ по удельному весу организаций, осуществляющих инновации всех типов (технологические, маркетинговые и организационные), представлено на рисунке 2 и в таблице 2.

При анализе полученных данных становится очевидным, что Уральский и Сибирский федеральные округа отличаются сбалансированным уровнем инновационной активности. В Приволжском федеральном округе удельный вес организаций, осуществляющих технологически инновации, превышает среднероссийский уровень, а лидерами по инновационному развитию являются Центральный и Северо-Западный федеральные округа - отклонение в большую сторону по 6 и 4 параметрам соответственно.

Более противоречивая ситуация складывается в Южном федеральном округе. С одной стороны, доля организаций в сфере сель- 


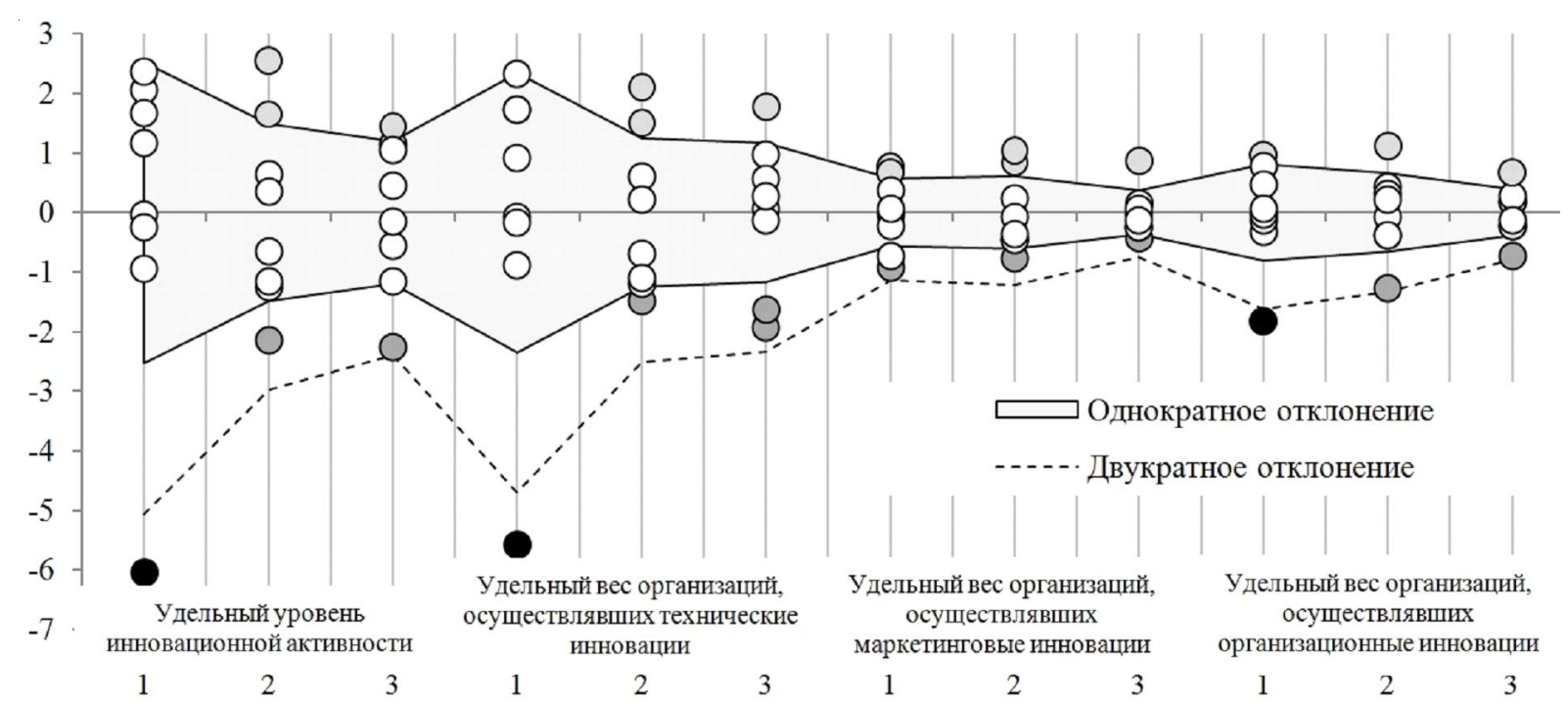

Рис. 2. Отклонение параметров удельного веса организаций, осуществляющих технические, маркетинговые и организационные инновации, от среднего уровня по Российской Федерации:

1 - промышленное производство; 2 - все виды экономической деятельности сферы услуг; 3 - сельское хозяйство

Примечание. Составлено автором.

Таблица 2

\section{Распределение федеральных округов Российской Федерации в зависимости от среднеквадратичного отклонения от усредненного параметра внутри каждой группы}

\begin{tabular}{|c|c|c|c|c|c|c|c|c|c|c|c|c|}
\hline \multirow{3}{*}{ Федеральный округ } & \multirow{2}{*}{\multicolumn{3}{|c|}{$\begin{array}{c}\text { Совокупный уровень } \\
\text { инновационной } \\
\text { активности }\end{array}$}} & \multicolumn{9}{|c|}{$\begin{array}{c}\text { Удельный вес организаций, осуществляющих инновации } \\
\text { отдельных типов, в общем числе организаций }\end{array}$} \\
\hline & & & & \multicolumn{3}{|c|}{$\begin{array}{c}\text { Технологические } \\
\text { инновации }\end{array}$} & \multicolumn{3}{|c|}{$\begin{array}{c}\text { Маркетинговые } \\
\text { инновации }\end{array}$} & \multicolumn{3}{|c|}{$\begin{array}{c}\text { Организационные } \\
\text { инновации }\end{array}$} \\
\hline & 1 & 2 & 3 & 1 & 2 & 3 & 1 & 2 & 3 & 1 & 2 & 3 \\
\hline Центральный ФО & $=$ & $\uparrow$ & $=$ & $=$ & $\uparrow$ & $=$ & $\uparrow$ & $\uparrow$ & $=$ & $\uparrow$ & $\uparrow$ & $=$ \\
\hline Северо-Западный ФО & $=$ & $\uparrow$ & $=$ & $=$ & $\uparrow$ & $=$ & $=$ & $\uparrow$ & $\uparrow$ & $=$ & $=$ & $=$ \\
\hline Южный ФО & $=$ & $=$ & $\uparrow$ & $=$ & $=$ & $\uparrow$ & $=$ & $=$ & $\downarrow$ & $=$ & $=$ & $=$ \\
\hline Северо-Кавказский ФО & $\downarrow \downarrow$ & $\downarrow$ & $\downarrow$ & $\downarrow \downarrow$ & $\downarrow$ & $\downarrow$ & $\downarrow$ & $\downarrow$ & $=$ & $\downarrow \downarrow$ & $\downarrow$ & $\downarrow$ \\
\hline Приволжский ФО & $=$ & $=$ & $=$ & $=$ & $=$ & $=$ & $\uparrow$ & $=$ & $=$ & $=$ & $=$ & $=$ \\
\hline Уральский ФО & $=$ & $=$ & $=$ & $=$ & $=$ & $=$ & $=$ & $=$ & $=$ & $=$ & $=$ & $=$ \\
\hline Сибирский ФО & $=$ & $=$ & $=$ & $=$ & $=$ & $=$ & $=$ & $=$ & $=$ & $=$ & $=$ & $=$ \\
\hline Дальневосточный ФО & $=$ & $=$ & $=$ & $=$ & $=$ & $\downarrow$ & $\downarrow$ & $=$ & $=$ & $=$ & $=$ & $\uparrow$ \\
\hline $\begin{array}{l}\text { Среднеквадратичное } \\
\text { отклонение }(S)\end{array}$ & 2,53 & 1,49 & 1,2 & 2,35 & 1,25 & 1,17 & 0,57 & 0,61 & 0,37 & 0,81 & 0,66 & 0,39 \\
\hline
\end{tabular}

Примечание. Составлено автором. Принятые обозначения: 1 - промышленное производство; 2 - все виды экономической деятельности сферы услуг; 3 - сельское хозяйство.

ского хозяйства, нацеленных на техническую модернизацию предприятий, превышает аналогичный показатель по Центральному федеральному округу (4,6 \% против $3,8 \%$ ), но маркетинговые инновации, связанные с освоением новых рынков сбыта и расширением состава потребителей сельскохозяйственной продукции, внедряются куда реже $(0,1 \%$ от обследованных организаций, при среднем показателе в $0,53 \%$ ).
Прямо противоположная ситуация наблюдается в Дальневосточном федеральном округе: удельная доля сельскохозяйственных организаций, применяющих усовершенствованные процессы или способы производства, составляет $1,2 \%$ и находится в диапазоне перехода от одно- к двукратному среднеквадратичному отклонению от нормирующего значения (2,8 \%), однако кризис идей по технологической модернизации 
сельскохозяйственного производства компенсировался всплеском инновационной активности по внедрению организационных решений, направленных на стимулирование роста производительности труда в этой сфеpe $(1,6 \%$ предприятий при среднем значении в $0,92 \%)$.

Аутсайдером среди всех федеральных округов Российской Федерации по внедрению инноваций любого типа является Северо-Кавказский федеральных округ. Из 12 отслеживаемых официальной статистикой параметров округ занимает последние места по 11 из них, а по удельному весу организаций, осуществляющих технологические и организационные инновации в промышленности приближается к опасно критическому барьеру перехода от дву- к трехкратному отклонению от среднеквадратичного параметра.

Таким образом, для сокращения региональной дифференциации при внедрении передовых практик в производственный процесс необходимо учитывать тип инновационной активности. В частности, с нашей точки зрения, дальнейшее массовое проникновение технологических инноваций во все звенья производственной цепочки должно четко следовать общемировым трендам цифровизации производства, где ключевым фактором успеха инновационно ориентированных компаний является поиск наиболее перспективных инвестиционных проектов еще на этапе подачи патентной заявки.

По привлекательности для инвестирования цифровые инструменты можно условно разделить на три категории, характеризующие ту или иную стадию их жизненного цикла:

- зрелость: технология нашла своего потребителя, получила широкое распространение, но дальнейший рост инвестиционной активности должен быть связан с поиском новых сфер применения или переходом на новый виток развития;

- устойчивый рост: технологии обладают не до конца раскрытым потенциалом для коммерческого использования, но на рынке массовых цифровых продуктов существует несколько аналогичных предложений, предназначенных для сходной целевой аудитории;

- прорывной тренд: технология находится на этапе тестирования пилотных проектов, со- ответствует потребительским предпочтениям заказчиков, но для ее масштабирования и использования необходимы специфические компетенции, редкие на современном рынке труда.

Ежегодное увеличение объемов данных, обеспечивающих виртуализацию и автоматизацию управления производственным процессом, рост электронной коммерции, распространение систем промышленного Интернета требуют постоянного увеличения пропускной способности мобильных сетей связи (Mobile Networks). В 2019 г. объем рынка мобильных сетей связи составил 890 млрд долл., но данная технология является одной из наиболее зрелых, и взрывной рост инвестиционной активности в этом сегменте связан с развертыванием технологии связи пятого поколения (5G). По сравнению с 2017 г. количество опубликованных патентов в этой сфере увеличилось в два раза, что свидетельствует о ее безусловной практической значимости [Мониторинг ...; Индикаторы цифровой экономики, 2019].

К технологиям, отличительным признаком которых является устойчивый рост научно-исследовательской, инвестиционной и патентной активности, следует отнести: интернет вещей (объем рынка в 2019 г. составил 214 млрд долл., но к 2025 г. прогнозируется его увеличение в 4,3 раза - до 934 млрд долл.), компоненты робототехники и сенсорики (57 млрд долл. и 147 млрд долл. соответственно) и методы анализа больших данных (46 млрд долл. и 132 млрд долл. соответственно) [Аналитический обзор ...; Большие данные ...].

Устойчивый рост инвестиций в данные технологии объясняется появлением доступных платформ и приложений, облегчающих их внедрение в технологические процессы, запуском процесса стандартизации, снижением стоимости хранения данных, повышением доступности облачных сервисов для обработки данных и увеличением емкости носителей информации.

К прорывным технологиям относятся: технологии искусственного интеллекта и ведение распределенного реестра (Blockchain).

По сравнению с 2017 г. произошло увеличение объемов патентования в сфере технологий искусственного интеллекта на $17 \%$, рост 
инвестиций составил $46 \%$, а количество научных публикаций выросло на 30 \%. В 2018 г. главной темой Всемирного экономического форума в Давосе стало обсуждение этики применения искусственного интеллекта. К 2025 г. ожидаемый объем мирового рынка в этой сфере увеличится в 6,68 раза (с 29 млрд долл. до 191 млрд долл.), и на текущий момент технология искусственного интеллекта уже широко внедряется в процесс автоматизации логистики производства, а также в сферу умных сетей электроснабжения (Smart Grid), обработки естественного языка (Natural Language Processing), компьютерного зрения (Computer Vision) и распознавания речи (Speech Recognition).

Рост безналичных платежей, распространение технологий биометрической идентификации, а также повышение требований к прозрачности трансакций привели к тому, что в 2018 г. количество научных статей, посвященных технологии распределенного реестра (Blockchain) выросло более чем 1,5 раза, объем инвестиций в ее разработку увеличился в 4 раза, а рост спроса на профильных специалистов в этой сфере превысил 5,17 раза по отношению к 2017 году. На текущий момент объем рынка Blockchain составляет 1 млрд долл., но за следующие 5 лет он вырастет не менее чем в 28 раз и составит 28,3 млрд долл. [Мониторинг ...; Индикаторы цифровой экономики, 2019].

Таким образом, в странах Западной Европы, где партнерство с ИКТ-индустрией инициировало массовое проникновение цифровых технологий в производство и сферу услуг, инновационная политика нацелена не только на рост производительности труда, но и на решение социальных проблем, связанных прежде всего с обеспечением продовольственной безопасности, охраной окружающей среды, снижением потребления топлива, повышением продолжительности жизни населения. В сфере сельского хозяйства к подобным прорывным направлениям можно отнести технологии интернета вещей (agroIoT) и геоаналитики (GIS / Spatial Analytics) [Цифровая трансформация ... , 2019], в промышленности - компоненты робототехники, сенсорики и искусственного интеллекта, обеспечивающие снижение трудозатрат и позволяющие осуществлять все виды деятельности в условиях, опасных для жизни и здоровья человека, для банковского или любого иного сервисного сектора - ведение распределенного реестра (Blockchain), технологии биометрической идентификации и методы анализа больших данных (Big Data). В качестве инструмента мониторинга точек роста производительности труда и популяризации передового опыта должна выступить национальная информационная цифровая база данных, объединяющая производителей, потребителей, предприятия розничной торговли и оптового сбыта, транспортную, таможенную, налоговую службы, а также научно- исследовательские институты и образовательные организации.

С другой стороны, для организационных и маркетинговых инноваций, которые связаны в первую очередь с укреплением кадрового и управленческого потенциала, в качестве элементов масштабирования, наиболее успешно зарекомендовавших себя в странах с развитой цифровой экономикой решений, следует выделить:

- инвестирование в развитие федеральных лабораторий, исследовательских центров и лабораторий для сближения предметной области научных разработок с целями и задачами, стоящими перед реальным сектором экономики;

- комплексное развитие цифровой грамотности населения.

Решение последней задачи предполагает увеличение государственной поддержки программ переобучения и повышения квалификации населения, что является стратегическим приоритетом развития Европейского союза на период до 2020 г. [Europe 2020 Strategy], а значимость неакадемических (дистанционных) форм распространения знаний не раз подчеркнута в целом ряде программных документов, призванных стимулировать «цифровизацию» национальных экономик: «Национальный план развития ИКТ» (Сингапур), «Индустрия 4.0» (Германия), «Smart America Challenge», «BigData R\&D», «Industrial Internet Consortium» (США), «Дорожная карта развития IоТ до 2020 г.» и «Интернет Плюс» (Китай) и т. д.

Актуальность для Российской Федерации социально ориентированных направлений сокращения региональной дифференциации инновационной активности обусловлена рядом причин. 
1. Растущий уровень технологической оснащенности производства, а также все более высокие ожидания, которые возлагает современная экономика на эффект цифровизации, требуют сокращения цепочки внедрения всех вновь созданных или усовершенствованных технологий за счет синхронизации спроса на научные исследования и возможностей его удовлетворения со стороны отечественных разработчиков средств ИКТ. Вместе с тем по сравнению с 2017 г. при росте ВВП на 2,3 \% произошло сокращение внутренних затрат на исследования и разработки на $8,5 \%$. В постоянных ценах соотношение составило $89,4 \%$, что является минимальным значением за период с 2010 по 2018 г. [Наука ..., 2019].

2. За период с 2011 по 2018 г. число специалистов в области информационно-коммуникационных технологий в странах Евросоюза увеличилось на $39,1 \%$, что более чем в 6 раз превышает рост общего числа занятых по экономике ЕС в целом $(6,5 \%)$. На текущий момент в Финляндии ИКТ-индустрия обеспечивает работой $6,8 \%$ занятого населения, в Швеции - 6,6 \%, в Эстонии и Великобритании $-5,1 \%$ и $5,0 \%$ соответственно, но трудности по найму персонала для внедрения высокотехнологических проектов продолжают испытывать руководители более чем 41 \% европейских предприятий, а для их дальнейшего ведения и обслуживания - $37 \%$ [Accenture ...].

В Российской Федерации общее количество специалистов по информационнокоммуникационным технологиям составляет 1617,4 тыс. чел., или $2,24 \%$ от общей занятости. Обладателями сертификата высшего уровня квалификации являются 904,1 тыс. чел. $(1,25 \%)$, разработкой программного обеспечения и приложений занимается 654,4 тыс. чел. $(0,9 \%)$, а созданием баз данных - 249,7 тыс. чел. $(0,35 \%)$.

Подавляющее число специалистов по ИКТ всех групп квалификации сосредоточено в обрабатывающей промышленности $(14,2 \%)$, их привлекают при проведении научных исследований $(7,4$ \%), используют в системе государственного управления, обеспечения военной и социальной безопасности $(6,0 \%)$, однако в сфере образования задействовано лишь $2,8 \%$ специалистов по ИКТ, в здравоохранении - $2,7 \%$, а в сельском хозяйстве - 0,4 \% [Наука ..., 2019].

3. Согласно официальной статистике, обучением компьютерной грамотности на профессиональной основе занимается 6,3 тыс. чел., или $0,4 \%$ от числа специалистов по ИКТ [Индикаторы цифровой экономики, 2019]. Вместе с тем даже базовыми навыками работы с цифровыми технологиями обладают не более половины населения РФ. Если с текстовыми редакторами знакомы 41,1 \% населения в возрасте от 15 лет и старше, отправка электронных писем не вызывает затруднений у $36,8 \%$, то знаниями, позволяющими изменить конфигурацию операционной системы, владеют лишь 2,7 \% населения, а самостоятельно написать программное обеспечение могут не более $1,1 \%$.

4. В 2018 г. доступом к Интернету обладали $76,6 \%$ от общего числа домохозяйств. По сравнению с 2015 г. доля населения, которая не выходит в глобальную сеть и признает, что недостаток навыков лишает этой возможности, выросла с 12,3 до 14,6 \%, но основным сдерживающим фактором роста интернетаудитории остается отсутствие необходимости и желания выходить в Сеть (рост с 67,9 до $72,6 \%$ ).

Подавляющая часть пользователей Интернета ведет активную жизнь в социальных сетях (78\%), но для чтения или скачивания электронных книг и журналов ресурсы глобальной сети использует лишь 23 \% пользователей, финансовые операции осуществляют $39 \%$, информацией, связанной со здоровьем или услугами в области здравоохранения, интересуется $36 \%$, поиском образовательных курсов и тренингов $-8,8 \%$, поиском свободных вакансий $-8 \%$, а используют для дистанционного обучения - 3,1 \% [Индикаторы цифровой экономики, 2019].

В странах Западной Европы просмотр и изучение ресурсов глобальной сети не только выступает сферой досуга, но и широко используется в профессиональном плане. В Австрии и Великобритании читателями онлайновой периодики являются $64 \%$ и $72 \%$ пользователей соответственно. Меры по защите интеллектуальной собственности стимулировали рост доверия к участникам цифровых сделок и использования безналичных платежей, а воз- 
можность выхода на контакт с работодателем увеличили долю сетевого поиска вакансий до 17 и $25 \%$ соответственно.

Таким образом, российская интернетаудитория практически достигла своих пределов роста, и без разработки специального контента, привлекающего к использованию электронных средств распространения информации людей старших возрастных групп, специалистов с низким уровнем квалификации, желающих повысить свои цифровые навыки посредством дистанционного переобучения, сельских жителей, проживающих на удаленных от крупных населенных пунктов территориях, всплеска активности не произойдет.

\section{Выводы}

Основу цифровой экономики составляет стремление создать полностью автоматизированную систему товаропроизводства, способную через наблюдение, понимание и прогнозирование перейти к самоорганизации, но в условиях обострения глобальной конкуренции единственной возможностью добиться синергетического эффекта роста производительности труда является сокращение отраслевой и региональной дифференциации инновационной деятельности.

Исследование основных трендов цифровизации показало, что технологии развертывания мобильных сетей связи, интернета вещей, анализа больших данных, искусственного интеллекта и ведения распределенного реестра взаимосвязаны. Прогресс в одной области невозможен при отставании в смежной, и соблюдение баланса между спросом на инструменты цифровизации и предложением на рынке высокотехнологической продукции выступает базовым элементом перехода к новой стадии научно-технологического уклада (Индустрии 4.0).

Вместе с тем сопоставление и анализ инновационной деятельности в странах, находящихся на разных этапах построения цифровой экономики, позволяет сделать вывод о необходимости разработки индивидуального подхода к интенсификации инновационной восприимчивости. С нашей точки зрения, инвестирование лишь в технологическое развитие следует отнести к догоняющему сценарию разви- тия событий, поскольку крупные транснациональные компании, в числепервых осознавшие выгоду от использования платформенных технологий, стремительно завоевывают новые рынки сбыта, компенсируя понесенные затраты и предлагая запатентованные, но уже технически устаревшие разработки. С одной стороны, это сокращает инновационный цикл внедрения, но, с другой стороны, обрекает на долгосрочную зависимость от поставщиков комплектующих, а также требует выделения дополнительного финансирования на оплату труда иностранных специалистов по обслуживанию новой техники. В связи с этим следует обратить особое внимание на особенности формирования собственной страты профессионалов, стимулировать рост специалистов в сфере ИКТ, инвестировать в развитие человеческого капитала населения страны в целом.

Цифровая экономика коренным образом меняет рынок труда, ряд профессий теряет свою актуальность и упраздняется, что приводит к расширению горизонта возможностей для применения новых навыков и компетенций. В целях привлечения и закрепления молодых кадров в сфере научных исследований и разработок необходимо обеспечить если не опережающее, то хотя бы сопоставимое увеличение внутренних затрат на прикладные и фундаментальные научные исследования по сравнению с ростом валового внутреннего продукта страны.

В рамках механизма цифровизации структура специальностей в высших учебных заведениях должна претерпеть существенную трансформацию и опираться на модульное построение сетевых образовательных программ, при этом особое внимание должно быть уделено проблемам адаптации выпускников к работе в цифровой среде, популяризации мысли, что стремление к постоянному повышению профессиональных знаний является гарантом востребованности молодого специалиста при трудоустройстве, будущей стабильности отношений «работник - работодатель».

Таким образом, при формировании сбалансированной цифровой экосистемы необходимо ориентироваться не только на достижение максимальной продуктивности производства, но и учитывать весь спектр социальных вопросов, связанных с формированием гибких 
форм занятости на основе принципов саморегуляции воспроизводства трудовых ресурсов. Совмещение экономических и социальных механизмов цифровизации влияет на скорость интеграции высоких технологий в производственный процесс, способствует созданию единого цифрового рынка и укреплению доверия населения к цифровой среде.

\section{СПИСОК ЛИТЕРАТУРЫ}

Аналитический обзор рынка Big Data. - Электрон. текстовые дан. - Режим доступа: https://habr. com/company/moex/blog/256747/ (дата обращения: 17.03.2020). - Загл. с экрана.

Большие данные в цифровой экономике: товар или национальное достояние. - Электрон. текстовые дан. - Режим доступа: http://tass.ru/pmef2017/articles/4273948 (дата обращения: 16.03.2020). - Загл. с экрана.

Индикаторы инновационной деятельности: 2019 : стат. сб. / Л. М. Гохберг [и др.]. - М. : НИУ ВШЭ, 2019.-376 c.

Индикаторы цифровой экономики: 2019 : стат. сб. / Г. И. Абдрахманова [и др.]. - М. : НИУ ВШЭ, 2019. $-248 \mathrm{c}$.

Мониторинг глобальных трендов цифровизации 2019. - Электрон. текстовые дан. - Режим доступа: https://www.company.rt.ru/upload/ iblock/a86/3009_Rostelecom_trends_2019.pdf (дата обращения: 17.03.2020). - Загл. с экрана.

Наука. Технологии. Инновации: 2020 : крат. стат. сб. / Л. М. Гохберг [и др.]. - М. : НИУ ВШЭ, 2019. $-88 \mathrm{c}$.

Стратегия инновационного развития Российской Федерации на период до 2020 года. - Электрон. текстовые дан. - Режим доступа: http:// gov.garant.ru/SESSION/PILOT/main.htm (дата обращения: 17.03.2020) . - Загл. с экрана.

Стратегия развития информационного общества в Российской Федерации на 2017-2030 годы. Электрон. текстовые дан. - Режим доступа: http://kremlin.ru/acts/bank/41919 (дата обращения: 15.03.2020). - Загл. с экрана.

Цифровая трансформация сельского хозяйства России : офиц. изд. - М. : ФГБНУ «Росинформагротех», 2019. $-80 \mathrm{c}$.

Цифровая экономика Российской Федерации : программа, утв. распоряжением Правительства РФ от 28.07.2017 № 1632-р. - Электрон. текстовые дан. - Режим доступа: http://static. government.ru/media/files/9gFM4FHj4PsB79I5 v7yLVuPgu4bvR7M0.pdf (дата обращения: 04.03.2020). - Загл. с экрана.
Accenture : data base. - Electronic text data. - Mode of access: https://www.accenture.com/us-en/serviceaccenture-analytics-big-data-and-technology (date of access: 01.02.2020). - Title from screen.

Europe 2020 Strategy. - Electronic text data. - Mode of access: https://ec.europa.eu/eu2020/pdf/ COMPLET\%20EN\%20BAR ROSO $\% 20 \% 20 \%$ 20007\%20-\%20Europe\%202020\%20-\% 20EN\% 20version.pdf(date of access: 04.02.2020). - Title from screen.

IMD World Digital Competitiveness Ranking 2019. Electronic text data. - Mode of access: https:// www. imd.org/wcc/world-competitivenesscenter-rankings/world-competitivenessranking-2019/ (date of access: 14.02.2020). - Title from screen.

The Global Innovation Index 2019: Creating Healthy Lives - The Future of Medical Innovation. Electronic text data. - Mode of access: https:// globalinnovationindex.org (date of access: 14.02.2020). - Title from screen.

\section{REFERENCES}

Analiticheskiy obzor rynka Big Data [Big Data Market Analyst]. URL: https://habr.com/company/ moex/blog/256747/ (accessed 17 March 2020).

Bolshie dannye $v$ tsifrovoy ekonomike: tovar ili natsionalnoe dostoyanie [Big Data in the Digital Economy: Good or National Treasure]. URL: http://tass.ru/pmef-2017/articles/4273948 (accessed 16 March 2020).

Gokhberg L.M. et al. Indikatory innovatsionnoy deyatelnosti: 2019: stat. sb. [Indicators of Innovation. 2019. Statistical Compilation]. Moscow, NIU VShE, 2019.376 p.

Abdrakhmanova G.I. et al. Indikatory tsifrovoy ekonomiki: 2019: stat. sb. [Digital Economy Indicators: 2019: Statistical Digest]. Moscow, NIU VShE, 2019.248 p.

Monitoring globalnykh trendov tsifrovizatsii 2019 [Monitoring of Global Digitalization Trends 2019]. URL: https://www.company.rt.ru/upload/ iblock/a86/3009_Rostelecom_trends_2019.pdf (accessed 17 March 2020).

Gokhberg L.M. et al. Nauka. Tekhnologii. Innovatsii: 2020: krat. stat. sb. [Science. Technology. Innovation. 2020. Brief Statistical Compilation]. Moscow, NIU VShE, 2019. 88 p.

Strategiya innovatsionnogo razvitiya Rossiyskoy Federatsii na period do 2020 goda [Strategy of Innovative Development of the Russian Federation for the Period Until 2020]. URL: http:// gov.garant.ru/SESSION/PILOT/main.htm (accessed 17 March 2020). 


\section{РЕГИОНАЛЬНАЯ ЭКОНОМИКА}

Strategiya razvitiya informatsionnogo obshchestva $v$ Rossiyskoy Federatsii na 2017-2030 gody [The Development Strategy of the Information Society in the Russian Federation for 2017-2030]. URL: http://kremlin.ru/acts/bank/41919 (accessed 15 March 2020).

Tsifrovaya transformatsiya selskogo khozyaystva Rossii: ofits. izd. [Digital Transformation of Russian Agriculture. Official Edition]. Moscow, FGBNU «Rosinformagrotekh», 2019.80 p.

Tsifrovaya ekonomika Rossiyskoy Federatsii: programma, utv. rasporyazheniem Pravitelstva RF ot 28.07.2017 № 1632-r. [Digital Economy of the Russian Federation. Program Approved by the Order of the Government of the Russian Federation Dated July 28, 2017 No. 1632-r]. URL: http://static. government.ru/media/files/9gFM4FHj4PsB79I5v 7yLVu Pgu4bvR7M0.pdf(accessed 4 March 2020).
Accenture: Data Base. URL: https://www. accenture.com/us-en/service-accentureanalytics-big-data-and-technology (accessed 1 February 2020).

Europe 2020 Strategy. URL: https://ec.europa.eu/ eu $2020 / \mathrm{pdf} / \mathrm{COMPLET} \% 20$ E N \% 20 BARROSO\%20\%20\%20007\%20-\%20 Europe\%202020\%20-\%20EN\%20version.pdf (accessed 4 February 2020).

IMD World Digital Competitiveness Ranking 2019. URL: https://www. imd.org/wcc/worldcompetitiveness-center-rankings/worldcompetitiveness-ranking-2019/ (accessed 14 February 2020).

The Global Innovation Index 2019: Creating Healthy Lives-The Future of Medical Innovation. URL: https://globalinnovationindex.org (accessed 14 February 2020).

\section{Information About the Author}

Maxim N. Osovin, Candidate of Sciences (Economics), Senior Researcher, Institute of Agrarian Problems of the Russian Academy of Sciences, Moskovskaya St, 94, 410012 Saratov, Russian Federation, himma@mail.ru, https://orcid.org/0000-0001-6621-2338

\section{Информация об авторе}

Максим Николаевич Осовин, кандидат экономических наук, старший научный сотрудник, Институт аграрных проблем РАН, ул. Московская, 94, 410012 г. Саратов, Российская Федерация, himma@mail.ru, https://orcid.org/0000-0001-6621-2338 